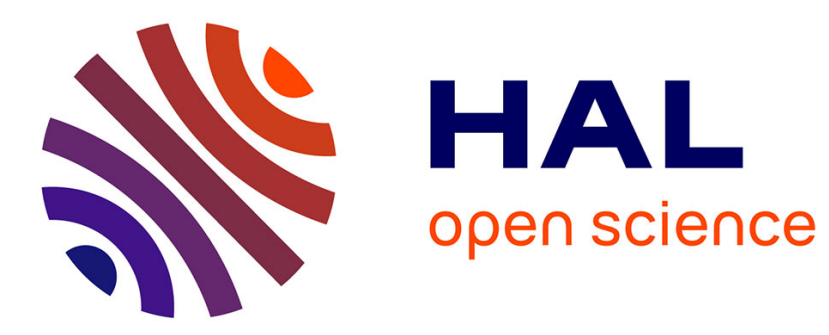

\title{
Large Data Sets, Nonlinearity and the Speed of Adjustment to Real Exchange Rate Shocks \\ Hyeyoen Kim
}

\section{To cite this version:}

Hyeyoen Kim. Large Data Sets, Nonlinearity and the Speed of Adjustment to Real Exchange Rate Shocks. Applied Economics, 2011, pp.1. 10.1080/00036846.2010.513676 . hal-00665456

\section{HAL Id: hal-00665456 https://hal.science/hal-00665456}

Submitted on 2 Feb 2012

HAL is a multi-disciplinary open access archive for the deposit and dissemination of scientific research documents, whether they are published or not. The documents may come from teaching and research institutions in France or abroad, or from public or private research centers.
L'archive ouverte pluridisciplinaire HAL, est destinée au dépôt et à la diffusion de documents scientifiques de niveau recherche, publiés ou non, émanant des établissements d'enseignement et de recherche français ou étrangers, des laboratoires publics ou privés. 


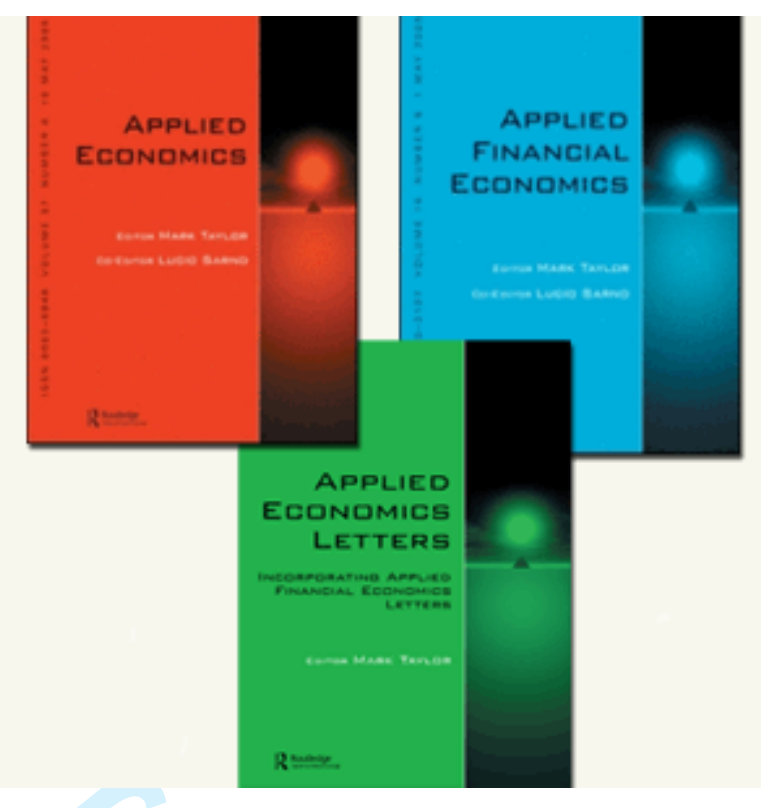

\section{Large Data Sets, Nonlinearity and the Speed of Adjustment to Real Exchange Rate Shocks}

\begin{tabular}{|r|l|}
\hline Journal: & Applied Economics \\
\hline Manuscript ID: & APE-2010-0328 \\
\hline Journal Selection: & Applied Economics \\
\hline Date Submitted by the \\
Author: & $30-$ Jul-2010 \\
\hline Complete List of Authors: & Kim, Hyeyoen; University of Leicester, economics dept \\
\hline JEL Code: & $\begin{array}{l}\text { F31 - Foreign Exchange < F3 - International Finance }<\mathrm{F}- \\
\text { International Economics }\end{array}$ \\
\hline Keywords: & diffusion indices, nonlinearity, real exchange rate \\
\hline
\end{tabular}

\section{SCHOLARONE ${ }^{\text {M }}$ Manuscripts}




\title{
Large Data Sets, Nonlinearity and the Speed of Adjustment to
}

\section{Real Exchange Rate Shocks}

\author{
Hyeyoen Kim \\ Department of Economics, University of Leicester
}

\begin{abstract}
A well known puzzle in international finance concerns the observed very slow speeds of adjustment of real exchange rates in response to shocks. In this paper, we explore whether allowing for a wide range of influences on the real exchange rate in a nonlinear framework can help resolve this puzzle. Using recently proposed econometric methods for summarising very large macroeconomic data sets into a small number of observable factors, we find that there is a long-run relationship between these factors and real exchange rates. When put into a nonlinear framework, we find that allowing for the effects of macroeconomic factors dramatically increases the measured speed of adjustment of the real exchange rate.
\end{abstract}

JEL CODE: F31

KEY WORDS: diffusion indices; nonlinearity; real exchange rates. 


\section{Introduction}

The empirical research effort on real exchange rates over the past two decades or so has tended to concentrate on necessary conditions for long-run purchasing power parity (PPP) to hold, in particular whether the real exchange rate reverts towards some constant equilibrium level over time. The upshot of this research programme is that, insofar as PPP does hold, it holds only in a very long run sense since shocks to the real exchange rate — which may be construed as deviations from PPP — tend to persist for long periods of time. In a survey of this literature, Rogoff (1996) describes the average measured speed of adjustment of real exchange rates as 'glacial', with a half-life of some three to five years. Given that the observed high volatility of real exchange rates under floating regimes suggestes that they must be driven largely by nominal shocks, and since it is hard to credit a half-life of adjustment of three to five years to nominal macroeconomic shocks, Rogoff terms this stylised of 'glacial' real exchange rate adjustment 'the PPP puzzle'.

There have been a number of attempts to resolve or at least explain Rogoff's PPP puzzle. One possibility is that adjustments of the real exchange rate towards PPP are nonlinear, since larger deviations may adjust back towards equilibrium faster than smaller deviations. This nonlinear adjustment may arise either because of transactions costs in international goods arbitrage (Balke and Fomby, 1997; Taylor et al, 2001; Imbs et al, 2003, 2005 ${ }^{1}$ ) or because of the presence of heterogeneous foreign exchange market agents that have competing views of the equilibrium rate (Kilian and Taylor, 2003), or because the authorities are more likely to intervene in the foreign exchange market when there are large deviations from exchange rate equilibrium (Taylor, 2004; Reitz and Taylor, 2007). By modelling the adjustment process towards equilibrium as a nonlinear process, researchers have indeed found that the speed of adjustment of the real exchange rate is significantly raised (Taylor et al., 2001; Kilian and Taylor, 2003), thus making some progress towards resolving the PPP puzzle.

In more recent work, however, researchers have also analysed whether time variation in the equilibrium real exchange rate may be modelled within a nonlinear framework, largely through an examination of whether the real exchange rate is impacted by international differences in aggregate factor productivity (Paya and Peel, 2006; Lothian and Taylor, 2007). By allowing for time variation in the equilibrium real

\footnotetext{
${ }^{1}$ The essence of the Imbs et al. (2005) study is that transactions costs generate differing speeds of adjustment at a disaggregated goods level that translate into an econometric bias in aggregate studies that employ linear econometric techniques.
} 
exchange rate, this work therefore moves away from examining necessary conditions for long-run PPP (mean-reversion of the real exchange rate towards a constant equilibrium) towards examining the speed of adjustment of the real exchange rate towards an equilibrium that may in fact vary over time. While productivity differentials are obvious candidates to examine for their effect on the equilibrium real exchange rate, a less restrictive analysis would allow for the real exchange rate to be impacted by a wide range of macroeconomic variables. Indeed, the failure properly to control for these variables in econometric studies may in part be responsible for the observed slow speed of real exchange rate adjustment. The purpose of this paper, therefore, is to investigate this possibility. In particular, we combine the diffusion index or factor method of Stock and Watson (2002a,b), which allows large amounts of data to be summarised parsimoniously, with linear and nonlinear models of real exchange rate adjustment. ${ }^{2}$

The remainder of the paper is organised as follows. The next section briefly describes the estimation of nonstationary macroeconomic factors and the nonlinear econometric techniques that we employ. In Section III we describe the data and some preliminary econometric results. Section IV presents our fitted nonlinear models and measures the effect on the measured speed of real exchange rate adjustment of introducing diffusion indices into the analysis. A final section concludes.

\section{Model Specification}

\section{1 Summarising large data sets}

The main advantage of factor models is to summarise the information in large data sets in a parsimonious fashion. Suppose that $X_{t}$ denotes an $n$-dimensional vector of $I(1)$ time series variables at time $t$, where $n$ may be very large. If $X_{t}$ is described by a factor model, it can be written as the sum of two orthogonal components:

$$
X_{t}=\Lambda_{t} F_{t}+\xi_{t}
$$

where $X_{t}=\left(x_{1 \mathrm{t}} \ldots x_{\mathrm{nt}}\right)^{\prime}$ and $\xi_{t}$ is the $(\mathrm{n} \times 1)$ idiosyncratic disturbance, which may be serially correlated. $F_{t}$ is the $(\mathrm{r} \times 1)$ vector of integrated process latent common factors such that

$$
F_{t}=F_{t-1}+u_{t}
$$

\footnotetext{
${ }^{2}$ Our investigation is at least partly inspired by the recent study of Bernanke, Boivin and Eliasz (2005), who find that by using the diffusion index methods due to Stock and Watson (2002a,b) they are able to solve the 'price puzzle' of monetary economics - namely that vector autoregressive simulations of small macro systems typically generate an initial price rise following a monetary tightening.
} 
where $u_{t}$ is a vector zero-mean $I(0)$ process. $F_{t}$ is, however, unobservable. There are several indirect ways to estimate unobservable factors. In this study, we use a two-step principal components method, following Stock and Watson (2002a) and Bai (2004). ${ }^{3}$

Since the principal components are by construction orthogonal to one another, there is no redundant information in individual factors. The estimated common factors are $I(1)$ processes since the $I(1)$ process $X_{t}$ is represented in levels.

In practice, $n$, the number of time series making up $X_{t}$, may be very large - of the order of fifty or a hundred. If most of the variation in $X_{t}$ is contained in the first $r$ common factors, however, then the dimensionality of the data problem may be reduced from $n$ to $r$, and $r$ will typically be a small number. Insofar as the resulting factors or diffusion indices can be used to augment an econometric model, the applied modeller may then be able to reflect the complexities of the economy in a parsimonious fashion with a workable number of degrees of freedom.

\section{2 Nonlinear real exchange rate adjustment}

Smooth transition autoregressive (STAR) models are introduced in econometrics literature by Granger and Teräsvirta (1993). In STAR model, the speed of adjustment towards equilibrium takes place in every period but the speed varies smoothly with the extent of the deviation from equilibrium. The STAR model is adequate to explain the nonlinear feature of real exchange rates, being employed by a number of researchers as discussed in Section 2. Among smooth transition functions, we focus on the exponential smooth transition autoregressive or ESTAR specification, which implies symmetric adjustment above and below equilibrium and which has been found to be particularly applicable to real exchange rates. The general ESTAR specification for a time series process $q_{\mathrm{t}}$ may be written:

$$
q_{t}=\sum_{j}^{p} \alpha_{j} q_{t-j}+\sum_{j}^{p} \beta_{j}\left[q_{t-j}-\mu\right] \Phi\left[\gamma ; q_{t-d}-\mu\right]+e_{t}
$$

where $\sum_{j}^{p} \alpha_{j}=1$ and $\sum_{j}^{p}\left[\alpha_{j}-\beta_{j}\right]<1$. In the present application, $q_{\mathrm{t}}$ is the real

\footnotetext{
3 This involves solving the eigenvalue problem for the sample covariance matrix: $\Xi_{0} Y_{r}=Y_{r} D_{r}$ where $\Xi_{0}$, estimated as $X X^{\prime} /\left(T^{2} N\right)$ is the covariance matrix of the standarised data matrix for a sample size T, $X=\left[\begin{array}{llll}X_{1} & X_{2} & \ldots & X_{T}\end{array}\right]^{\prime}$ and $Y_{r}=\left[\mathrm{y}_{1} \ldots \mathrm{y}_{\mathrm{r}}\right]$ is the $(n \times r)$ matrix whose columns are the $r$ eigenvectors that corresponds with the first $r$ largest eigenvalues of covariance matrix, $\Xi_{0}$, which we defined here as first $\mathrm{r}$ principal components.
} 
exchange rate defined as

$$
q_{t}=s_{t}-p_{t}+p_{t}^{*}
$$

where $s_{t}$ is the logarithm of the nominal exchange rate (domestic price of foreign currency) and $p_{t}$ and $p_{t}{ }^{*}$ denote the logarithms of the domestic and foreign price level, respectively; $\Phi\left[\gamma ; q_{t-\mathrm{d}}-\mu\right]$ is the exponential transition function specified as

$$
\Phi\left[\gamma ; q_{t-d}-\mu\right]=1-\exp \left[-\gamma\left(q_{t-d}-\mu\right)^{2}\right]
$$

The exponential transition function determines the degree of mean reversion and is itself governed by the nonlinear adjustment parameter, $\gamma$, which effectively determines the speed of mean reversion and the parameter $\mu$ which is the equilibrium level of real exchange rates. $\Phi\left[\gamma ; q_{\mathrm{t}-\mathrm{d}^{-}} \mu\right]$ is bounded by zero to unity with symmetrically inverse bell-shaped around zero. The transition parameter $\gamma>0$, determines the speed of transition between the two extreme regimes of random walk and different $\operatorname{AR}(p)$ specification, with lower absolute values of $\gamma$ implying slower transition.

When the real exchange rate is close to the equilibrium level $\mu$, for instance, the nonlinear part of equation (3) disappears as $\Phi(0)=0$, and the real exchange rate is close to $\operatorname{AR}(\mathrm{p})$ model:

$$
q_{t}=\sum_{j}^{p} \alpha_{j} q_{t-j}+e_{t}
$$

As departures from the equilibrium increase, however, the argument of the transition function gets larger and larger and, in the limit, the transition function approaches unity: $\lim _{|x| \rightarrow \infty} \Phi\left[\gamma ; q_{\mathrm{t}-\mathrm{d}^{-}} \mu\right]=1$. In the limit, therefore, (3) becomes a difference AR (p) model:

$$
q_{t}=\sum_{j}^{p}\left[\alpha_{j}+\beta_{j}\right] q_{t-j}+\sum_{j}^{p} \beta_{j} \mu+e_{t}
$$

with a correspondingly difference speed of mean reversion so long as $\alpha_{j} \neq 0$ in (3) for at least one value of $\mathrm{j}$. For intermediate deviations of the real exchange rate from equilibrium, the process will display a finite speed of adjustment.

By combining the factors in a nonlinear function, the equilibrium real exchange rate becomes time varying and dependent on macroeconomic fundamentals estimated by the common factors or diffusion indices. We term ESTAR models of this kind, in which macroeconomic fundamentals have been added into the specification by mean of factors, 'factor-augmented ESTAR' or FESTAR models.

Equation (3) implicitly assumes that the real exchange rate has a constant equilibrium, $\mu$, but we can relax this assumption by incorporating the long-run 
relationship between factors and the real exchange rate into the transition function if such a relationship exists. When the factors are included, equation (3) may be modified as

$$
q_{t}=\sum_{j}^{p} \alpha_{j} q_{t-j}+\sum_{j}^{p} \beta_{j}\left[q_{t-j}-b F_{t-j}\right] \Phi\left[\gamma ; q_{t-d}-b F_{t-d}\right]+e_{t}
$$

where $F_{t}$ is the vector of factors characterising the common stochastic components of the macroeconomy data.

By the specification of (8), the key innovation of this paper is the incorporation of diffusion indices into the determinants of the long-run equilibrium real exchange rate. It is already known that allowing for nonlinearities in real exchange rate adjustment mitigates the PPP puzzle (Taylor et al. 2001). Moreover, previous attempts to allow for time-variation of the equlibrium real exchange rate in a nonlinear framework have typically focused on a very small number of variables such as relative productivity (Paya and Peel, 2006; Lothian and Taylor, 2007). By allowing for the effect a large number of macroeconomic factors on the real exchange rate in the context of nonlinear adjustment, we wish to investigate whether a faster speed of real exchange rate adjustment can be ascertained.

\section{Data and Preliminary Analysis}

Our data base is composed of two parts, each covering a sample period from January 1973 through to June 2006. The first part consists of the monthly US dollar spot exchange rate for UK sterling, Japanese yen, and Australian dollar together with monthly observations on consumer price indices for the UK, Japan, Australia, and the US. The real exchange rate is constructed in logarithmic form as in Equation (6), with $s_{t}$ the US dollar price of foreign currency, $p_{t}$ the logarithm of the US consumer price index (CPI), and $p^{*}{ }_{t}$ as the logarithm of the CPI of the corresponding country.

The second part of our data base consists of large data sets of macroeconomic time series for the UK, Japan, Australia, and the US. The composition of the monthly data sets was determined by data availability which represents the real variables (real production, employment, orders, retail sales, etc.), nominal macroeconomic variables (e.g. monetary aggregates), asset prices (stock prices, interest rates, etc.), and international trade variables (import, exports, etc.). ${ }^{4}$ The each time series of data sets are transformed to be seasonally adjusted and logarithms are taken for for nonnegative

\footnotetext{
${ }^{4}$ Details of data sets are available from the authors on request.
} 
series which are not represented in percentage unit. The total number of time series collected was $75,81,49$, and 85 for the UK, Japan, Australia, and US, respectively. ${ }^{5}$

If the series are characterized by a few strong comovements, a small number of factors should account for a sizeable percentage of the overall variance while the remaining principal components have small marginal contribution. We found in each case that two factors appeared adequate and explained more than 30 percent of total variability.

As a preliminary exercise to investigate the long run relationship between real exchange rates and the common stochastic movements, we obtained a simple estimate of the long-run or fundamental equilibrium level of the real exchange rate by rotating two factors each from the home and foreign countries toward $q_{t}$ by running the following regression.

$$
q_{t}=a+\lambda_{1}^{\prime} \hat{F}_{1, t}+\lambda_{2}^{\prime} \hat{F}_{2, t}+\text { error }
$$

where $\hat{F}_{i, t}=\left(\hat{f}_{i, t} \hat{f}_{i, t}^{*}\right)$ for $i=1,2$ with $f_{i, t}$ and $f_{i, t}^{*}$ indicating the $i$-th home and foreign factors, respectively.

When we plot the actual logarithmic real exchange rate and our simple estimates of the factor-based fundamental levels for the whole sample period, there is clear evidence suggesting that the real exchange rate is explained by the stochastic trends summarized by factors. As illustrated in Figure 1, the movement of the real exchange rates seems to track the fundamental level and turning points look correct in general. The fact that factors fail to explain the high US dollar during the mid 1980s accords with the received wisdom that this was a period of large scale dollar overvaluation.

This exercise, however, is clearly very primitive and incomplete, given that the on either side of (9) are I(1) variables. In order to detect the common movement among these stochastic series in the long run, Johansen's cointegration analysis was therefore conducted. ${ }^{6}$ The results are reported in Table 1 , and indicate that we can reject at standard significance levels the the null hypothesis of no cointegration between the real exchange rate and the factor indices. Given this evidence of a long-run relationship between $q_{t}$ and $F_{t}$, we are motivated to construct the nonlinear real exchange rate

\footnotetext{
${ }^{5}$ For the Australian data, many series are on a quarterly basis and only available for a recent twenty-year period. Hence the volume of data which covers the last thirty-four years is smaller for Australia than for the other countries.

${ }^{6}$ As noted by Balke and Fomby (1997), linear cointegration analysis is still applicable in cases where adjustment towards that equilibrium is nonlinear.
} 
specification which includes factors as determinants of long-run equilibrium.

\section{Empirical Results}

\section{IV.1 Nonlinear estimation results}

When a long-run relationship exists between real exchange rates and factors, such a relationship should say something about the speed of adjustment of real exchange rates. For this purpose, we specify a model which combines the long-run relationship between factors and real exchange rates into a nonlinear system and investigate the persistence of shocks to the real exchange rate.

Following the procedure suggested by Teräsvirta (1994) for the specification and estimation of STAR models, we found that a first delay parameter is adequate, based on a set of nested likelihood ration tesets. Further, we tested the restrictions on the autoregressive parameters $\alpha=1, \beta=-1$ and in no case could we reject at the five percent significance level. These restrictions imply an equilibrium of the real exchange rate, in the neighborhood of which $q_{\mathrm{t}}$ is close to a random walk, becoming increasingly mean reverting with the absolute size of the deviation from equilibrium.

The fitted ESTAR models are reported in Table 2. The simple ESTAR model of real exchange rates was then modified as a factor-augmented ESTAR or FESTAR model by adding factors into the transition function. Initially, we included four factors in the FESTAR specification (two home factors and two foreign factors) such that:

$$
\begin{aligned}
& q_{t}=q_{t-1}-\left(q_{t-1}-\beta_{1} f_{1, t-1}-\beta_{2} f_{2, t-1}-\beta_{3} f_{1, t-1}^{*}-\beta_{4} f_{2, t-1}^{*}-c\right) \times \\
& \left\{1-\exp \left[-\gamma\left(q_{t-1}-\beta_{1} f_{1, t-1}-\beta_{2} f_{2, t-1}-\beta_{3} f_{1, t-1}^{*}-\beta_{4} f_{2, t-1}^{*}-c\right]^{2}\right\}+e_{t}\right.
\end{aligned}
$$

Following a general-to-specific specification search, we then arrived at our parsimonious FESTAR specifications which are presented in Table 3. All of these estimations were conducted using nonlinear least squares.

A notable feature of the results reported in Table 3 is that the estimated transition parameter, $\gamma$, is larger absolute value than in the FESTAR specifications than in the simpler ESTAR specifications. In both nonlinear models, ' $t$-statistics' of the estimated value of $\gamma$ suggest that it is significantly different from zero. However, standard $t$-values are not valid in this specification since the presence of a unit root under the null hypothesis complicates the testing procedure. ${ }^{7}$ We therefore calculated the empirical significance levels using Monte-Carlo simulation under the null

\footnotetext{
7 Analogous to the way in which the distribution of the Dickey-Fuller statistic cannot be assumed to be Student's $t$
} 
hypothesis assumption of a unit root $\mathrm{AR}(1)$ process, i.e. $\gamma=0^{8}$, and the resulting empirical marginal significance levels show strong support in favour of nonlinearity in $q_{\mathrm{t}}$ in both the ESTAR and FESTAR formulations.

\section{IV.2 Estimated half-lives of adjustment}

Based on the estimated models reported in Tables 2 and 3, we calculated the half-lives of a range of shocks to the real exchange rates. In contrast to the linear case, estimating half-lives is complicated in nonlinear models since the ultimate effect of a shock can vary depending on the state of the system at the time of the impact of the shock as well as on the sign and magnitude of the shock. In the present analysis we follow the approach of Koop et al. (1996) and Gallant et al. (1993) to estimate the generalised impulse response functions by Monte Carlo integration.

In particular, the impulse response function (IRF) is defined as the evolution of the effects of shocks on variables at $\mathrm{N}$ horizons expressed as $\{\operatorname{IRF}[1, \mathrm{~s}(\mathrm{t}), \mathrm{h}(\mathrm{t})]$, $\operatorname{IRF}[2, \mathrm{~s}(\mathrm{t}), \mathrm{h}(\mathrm{t})], \ldots, \operatorname{IRF}[\mathrm{N}, \mathrm{s}(\mathrm{t}), \mathrm{h}(\mathrm{t})]\} . s(t)$ is an arbitrary shock occurring at time $t$ and $h(t)$ indicates the history set of $q_{t}$. The IRF is defined as the distance between the path of $q$ which is expected to prevail at time $\mathrm{t}$ through $\mathrm{t}+\mathrm{N}$ following an additive shock of size $s(t)$ at time $\mathrm{t}$, and a baseline path assuming that a shock does not take place at time $\mathrm{t}$. Formally, this can be expressed as:

$$
\operatorname{IRF}[N, s(t), h(t)]=E[q(t+n) / s(t), h(t)]-E[q(t+n) / h(t)], n=1,2, \ldots N \text {. }
$$

In a nonlinear model, estimation of (11) is not simple due to the difficulties in generating n-period ahead expectations directly from available information at time $t$. In particular, the effects of future innovations cannot be simply set to an expected value of zero since the expected value of a nonlinear function of innovations will typically be non-zero.

As an alternative solution, Monte Carlo integration can be exploited. In the present analysis, 5,000 replications of the sample paths $(\mathrm{N}=100)$, based on the nonlinear specification in Table 2 and 3, with and without a shock of size $s$ at time $t$ are simulated by randomly drawn residuals as noise for future horizons. The realizations of the differences between the two paths with and without a shock are calculated and saved. We then move up one data point and conduct this procedure again. Once the difference of the simulated paths are stored for every data point from January 1973 through June

\footnotetext{
8 The method of estimation of the empirical significance levels follows the procedure described in Taylor et al. (2001).
} 
2006, the impulse response function is estimated as an average over all the simulated sequences of differences in the paths of the deviations from fundamental equilibrium with and without the shock. Therefore, the IRFs are conditional on the average history of the given $q_{\mathrm{t}}$ series.

Since the size of shock matters in a nonlinear system, five different sizes of shock were considered. With $s$ taken from the set $\{1,5,10,20,30\} .{ }^{9}$ This allows us to compare how large and small shocks affect real exchange rates over time in our two different nonlinear frameworks, ESTAR and FESTAR. In addition, for purposes of comparison, we also estimated simple AR(1) models and used them to estimate halflives of adjustment under the assumption of linearity.

Figures 2 and Table 4 summarise the estimated impulse response functions. As clearly illustrated, all of the impulse response functions show a nonlinear pattern with steeper degrees of mean reversion as the size of the shock increases. When the half-lives of shocks are compared between FESTAR and ESTAR, a faster speed of adjustment is found in the FESTAR case for all sizes of shocks considered and for all currencies. In the FESTAR model, for instance, the half-lives range from 3 to 30 months depending on the exchange rate, while the corresponding range is 5 to 70 months in ESTAR formulation.

Focusing on the FESTAR results, the fastest speed of adjustment is observed in dollar-sterling for a 30 percent shock, which has a half-life of only 3 months. For 1 percent shocks, the real exchange rate exhibits slow mean reversion consistent with a half-life as long as 30 months, as seen in dollar-Australian dollar, but this nevertheless still faster than implied by the univariate ESTAR model. Similarly, for Japan, the halflife of a 1 percent shock is much shortened with the inclusion of macro factors, reducing from 70 months in the estimated ESTAR formulation to just 24 months in the estimated FESTAR specification.

Compared to the half-lives estimated using a liner specification, our findings are consistent with the existing literature which shows that measured half-lives of adjustment of real exchange rate shocks are shorter when measured in an explicitly nonlinear framework. The innovation in the present study, however, is the finding that the measured half-life shrinks even further when diffusion indices or macro factors are added into the nonlinear system.

\footnotetext{
9 A shock of $s$ percent to the level of the real exchange rate is equivalent to adding $\log (1+\mathrm{s} / 100)$ to $q_{t}$; the half-life is the time taken for the impulse response function to fall below $0.5 \log (1+\mathrm{s} / 100)$.
} 


\section{Conclusion}

In this paper, we have shown that the information in large macroeconomic data sets is relevant for resolving a well known puzzle in international finance concerning the slow speed of adjustment of real exchange rates in response to shocks. In particular, using measures of macroeconomic factors that summarise large amounts of macroeconomic data, our estimated factor-augmented ESTAR, or FESTAR models are designed to incorporate the long-run relationship between real exchange rates and economic fundamentals into the nonlinear property of real exchange rates. Similar to the nonlinear ESTAR formulation employed in a number of previous studies of the real exchange rate, the FESTAR specification allows the real exchange rate to behave as a random walk near the equilibrium and as mean-reverting far away from the equilibrium in a nonlinear fashion, consistent with a number of theoretical analyses of the real exchange rate. In addition, however, the FESTAR specification allows the influence of a complex set of macroeconomic variables on the real exchange rate in a parsimonious fashion.

The FESTAR specification was applied to three major real exchange rates against the US dollar: dollar-sterling, dollar-yen, and US dollar-Australian dollar. When we estimate the half-life of real exchange rate adjustment using these estimation results, the FESTAR specification exhibits a much faster speed of mean reversion than univariate linear and nonlinear models. These results therefore suggest that the finding of slow mean reversion in the real exchange rate may result from a failure properly to allow for the wide range of macroeconomic influences on the equilibrium real exchange rate.

\section{References}

Bai, J. (2004). Estimating cross-section common stochastic trends in nonstationary panel data. Journal of Econometrics, 122, 137-183.

Balke, N. S. and Fomby, T. B. (1997). Threshold cointegration, International Economic Review, 38, 627-45.

Banerjee, A., Marcellino, M., and Osbat, C. (2005). Testing for PPP: should we use 
panel methods? Empirical Economics, 30, 77-91

Bernanke, B. and Boivin, J. and Eliasz, P. (2005). Measuring the effects of monetary policy: a factor-augmented vector autoregressive (FAVAR) approach. Quarterly Journal of Economics, 120, 387-422.

Boero, G.. and Marrocu, E. (2002). The performance of nonlinear exchange rate models: a forecasting comparison. Journal of Forecasting, 21, 513-542.

Clements, M. P. and Smith, J. P. (2001), Evaluating forecasts from SETAR models of exchange rate. Journal of international money and finance, 20, 133-148.

Clements, M. P. and Hendry, D. F. (2002). A Companion to Economic Forecasting, Blackwell, Oxford.

Cheung, Y. W. and Chinn, M. D. (1999). Macroeconomic implications of the beliefs and behaviour of foreign exchange traders. NBER Working Paper No. 7417.

Dumas, B. (1992). Dynamic equilibrium and the real exchange rate in a spatially separated world. Review of Financial Studies, 5, 153-180.

Eitrheim, Ø. and Teräsvirta, T. (1996). Testing the adequacy of smooth transition autoregressive models. Journal of Econometrics, 74, 59-75.

Gallant, A. R., Rossi, P. E., and Tauchen, G. (1993). Nonlinear dynamic structure, Econometrica, 61, 871-908.

Granger, C. and Teräsvirta, T. (1993). Modelling Nonlinear Economic Relationships. Oxford University Press; Oxford.

Groen, J.J.J. (2005). Exchange rate predictability and monetary fundamentals in a small multi-country panel, Journal of Money, Credit, and Banking, 37, 495-516.

Imbs, J., Mumtaz, H., Ravn, M.O. and Rey, H. (2003) Nonlinearities and Real Exchange Rate Dynamics, Journal of the European Economic Association, 1, 639-649.

Imbs, J., Mumtaz, H., Ravn, M.O. and Rey, H. (2005) PPP Strikes Back: Aggregation and the Real Exchange Rate, Quarterly Journal of Economics, 120, 1-43.

Kilian, L. and Taylor, M. P (2001). Why is it so difficult to beat the random walk forecast of exchange rates? Journal of International Economics, 60, 85-117.

Kilian, L. and Zha, T. (2002). Quantifying the uncertainty about the half-life of deviations from PPP, Journal of Applied Econometrics, 2002, 107-125.

Koop, G, Peresan, M. H. and Potters S. M.(1996). Impulse response analysis in nonlinear multivariate models. Journal of Econometrics, 74, 119-147. 
Lothian, J.R. and Taylor, M.P. (2007) Real Exchange Rates Over the Past Two Centuries : How Important is the Harrod-Balassa-Samuelson Effect? forthcoming, Economic Journal.

Mark, N. C., Sul, D. (2001) Nominal exchange rates and monetary fundamentals evidence from a small post-Bretton Woods panel. Journal of International Economics, $53,29-52$.

Meese, R. A., and Rogoff, K. (1983), Empirical exchange rate models of the seventies: do they fit out-of sample? Journal of International Economics, 3-24.

Michael, P. A., Nobay, R., and Peel, D. (1997). Transactions costs and nonlinear adjustment in real exchange rates: an empirical investigation. Journal of Political Economy, 105, 862-79

Mussa, M. (1976). The exchange rate, the balance of payments and monetary and fiscal policy under a regime of controlled floating, Scandinavian Journal of Economics, 78, 229-48.

Inoue, A. and Rossi, B. (2005). Monitoring and forecasting currency crises. Economics Department, Duke University (Working Paper N.05-02)

Paya, I and Peel, D. A. (2006), A new analysis of the determinants of the real dollarsterling rate: 1871-1994, Journal of Money, Credit and Banking, 38, 1971-1990.

Reitz, S. and Taylor, M.P. (2007) The coordination channel of foreign exchange intervention: a nonlinear microstructural analysis, forthcoming, European Economic Review.

Sarno, L. and Taylor, M. P. (2002). The Economics of Exchange Rates. Cambridge University Press, Cambridge.

Sercu, P., Uppal, R. and Van Hulle, C. (1995). The exchange rate in the presence of transactions costs: implication for tests of purchasing power parity, Journal of Finance, $50,1309-1319$.

Shintani, M., (2005). Nonlinear Forecasting Analysis Using Diffusion Indexes: An Application to Japan, Journal of Money, Credit, and Banking, 37, 517-538.

Stock, J. and Watson, M. (2002a). Macroeconomic forecasting using diffusion indexes. Journal of Business and Economic Statistics, 20, 147-162.

Stock, J. and Watson, M. (2002b). Forecasting using principal components from a large number of predictors. Journal of the American Statistical Association, 97, 1167-1179. 
Taylor, M. P., Peel. D. A., and Sarno, L. (2001). Nonlinear mean-reversion in real exchange rates: toward a solution to the purchasing power parity puzzles. International Economic Review, 42, 1015-1042.

Taylor, M. P. and Peel, D.A (2000). Nonlinear adjustment, long-run equilibrium and exchange rate fundamentals. Journal of International Money and Finance, 19, 33-53.

Taylor, M. P. (2004). Is official exchange rate intervention effective? Economica, 71, 111.

Taylor, A. M. and Taylor, M. P. (2004). The purchasing power parity debate, Journal of Economic Perspective, 14, 135-158.

Teräsvirta, T. (1994). Specification, estimation and evaluation of smooth transition autoregressive models. Journal of the American Statistical Association, 89, 208-2 
Table 1. Johansen cointegration tests

\begin{tabular}{lccc}
\hline & \multicolumn{3}{c}{ Statistics } \\
\cline { 2 - 4 } & Lags & Trace & Max \\
\hline UK & 12 & $86.80^{*}(0.001)$ & $35.80^{*}(0.029)$ \\
Japan & 11 & $82.33^{*}(0.003)$ & $30.82(0.110)$ \\
Australia & 9 & $73.64 *(0.024)$ & $38.28^{*}(0.013)$ \\
\hline \multicolumn{2}{l}{ Note: * indicates significance at the 5\% level for the null of no cointegration. ( ) indicate MacKinnon- } \\
Haug-Michelis p-values
\end{tabular}

Table 2. ESTAR estimated by country (Jan. 1973 - Jun. 2006)

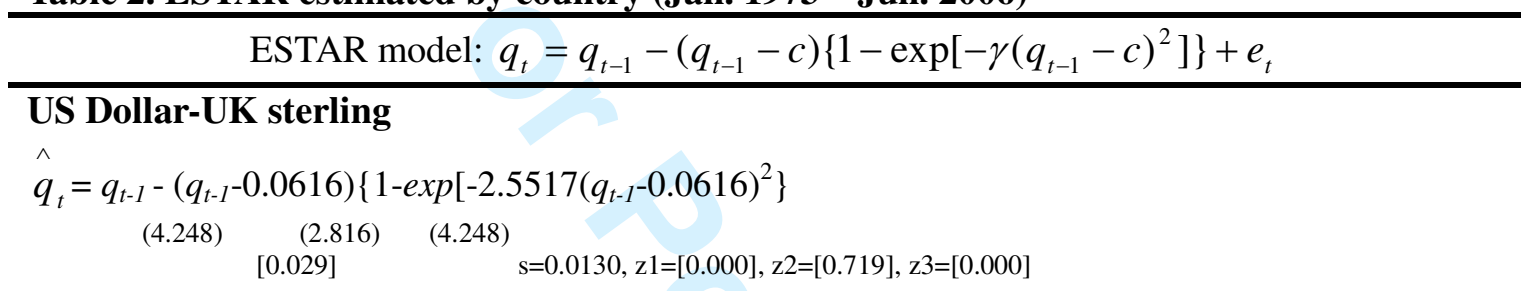

\section{US Dollar-Japanese Yen}

$$
\begin{aligned}
& \hat{q}_{t}=q_{t-1}-\left(q_{t-1}-0.2258\right)\left\{1-\exp \left[-0.8717\left(q_{t-1}-0.2258\right)^{2}\right\}\right.
\end{aligned}
$$

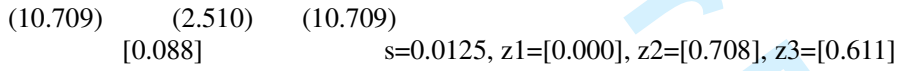

\section{US Dollar-Australian dollar}

$$
\begin{aligned}
& \hat{q}_{t}=q_{t-1}-\left(q_{t-1}-0.0395\right)\left\{1-\exp \left[-3.6232\left(q_{t-1}-0.0395\right)^{2}\right\}\right. \\
& (-3.081) \quad(2.711) \quad(2.911) \\
& \text { [0.033] } \mathrm{s}=0.0128, \mathrm{z} 1=[0.000], \mathrm{z} 2=[0.686], \mathrm{z} 3=[0.115]
\end{aligned}
$$

Notes: Figures in parenthesis are estimated 't-ratios'; $s$ is the standard error of the regression. $z 1$ is the Jarque-Bera test statistic for normality of the residuals; z2 is the Eitrheim-Teräsvirta test statistic for serial correlation up to order three; z3 is White's test statistic for heteroscedasticity. Figures in square brackets are marginal significance levels. The marginal significance levels for the estimated transition parameter 't-ratios' were calculated by Monte-Carlo simulation under the null hypothesis that the transition parameter was zero. 
Table 3: FESTAR estimates by country (Jan. 1973 - Jun. 2006)

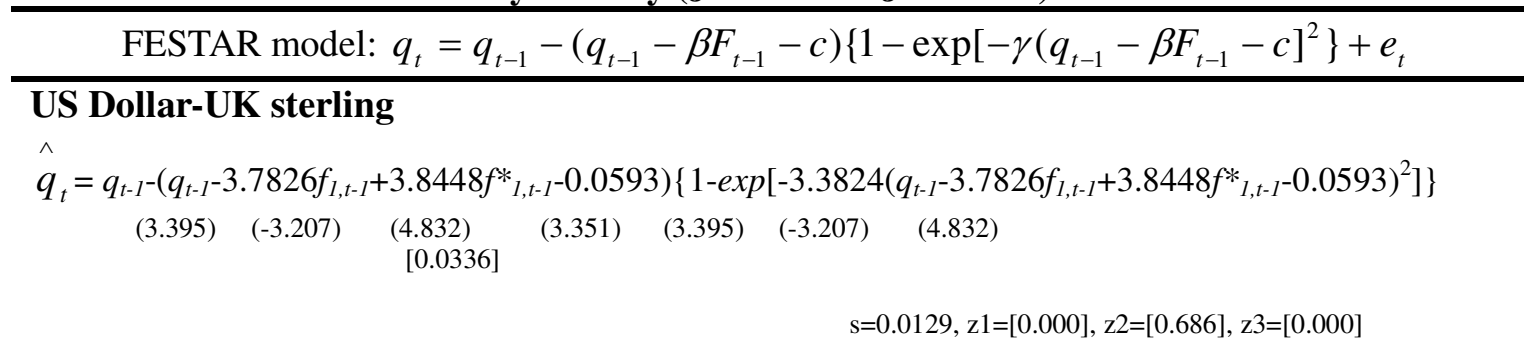

\title{
US Dollar-Japanese Yen
}

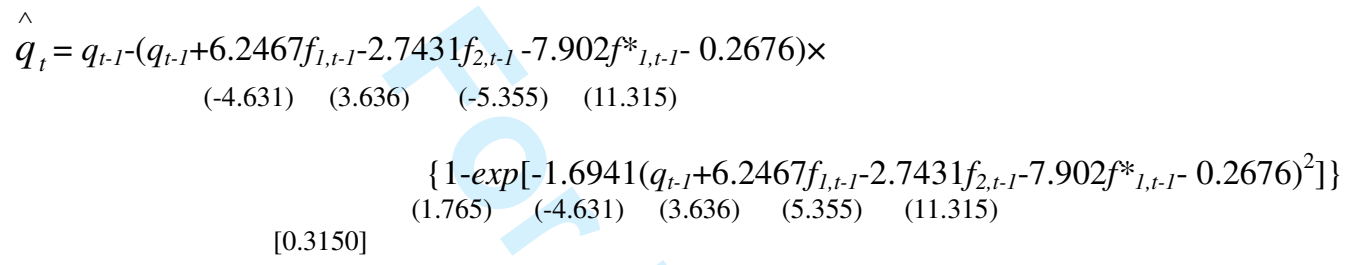

$\mathrm{s}=0.0122, \mathrm{z} 1=[0.000], \mathrm{z} 2=[0.695], \mathrm{z} 3=[0.119]$

US Dollar-Australian dollar

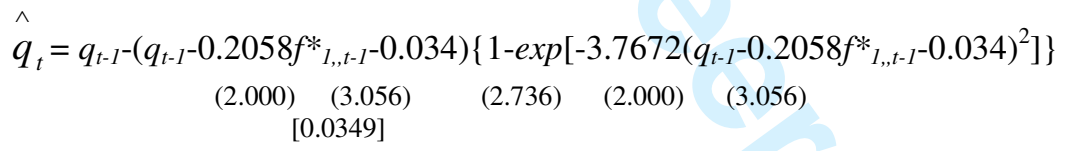

$\mathrm{s}=0.0128, \mathrm{z} 1=[0.000], \mathrm{z} 2=[0.711], \mathrm{z} 3=[0.197]$

\begin{abstract}
Notes: Figures in parenthesis are estimated 't-ratios'; $s$ is the standard error of the regression. $\mathrm{z} 1$ is the Jarque-Bera test statistic for normality of the residuals; z2 is the Eitrheim-Teräsvirta test statistic for serial correlation up to order three; z3 is White's test statistic for heteroscedasticity. Figures in square brackets are marginal significance levels. The marginal significance levels for the estimated transition parameter 't-ratios' were calculated by Monte-Carlo simulation under the null hypothesis that the transition parameter was zero.
\end{abstract}


Table 4. Estimated Half-lives Conditioning on Average Initial History

\begin{tabular}{clccccc}
\hline & Shock (\%) & $\mathbf{1}$ & $\mathbf{5}$ & $\mathbf{1 0}$ & $\mathbf{2 0}$ & $\mathbf{3 0}$ \\
\hline \multirow{2}{*}{ UK } & Linear AR & 26 & 26 & 26 & 26 & 26 \\
& ESTAR & 50 & 26 & 15 & 8 & 5 \\
& FESTAR & 24 & 14 & 9 & 5 & 3 \\
\hline \multirow{2}{*}{ JAPAN } & Linear AR & 43 & 43 & 43 & 43 & 43 \\
& ESTAR & 70 & 43 & 27 & 15 & 10 \\
& FESTAR & 24 & 18 & 14 & 7 & 5 \\
\hline \multirow{2}{*}{ AUSTRALIA } & Linear AR & 28 & 28 & 28 & 28 & 28 \\
& ESTAR & 40 & 20 & 12 & 6 & 4 \\
& FESTAR & 30 & 17 & 10 & 5 & 4 \\
\hline
\end{tabular}

Notes: The half-lives for the estimated nonlinear ESTAR and FESTAR models were calculated by Monte Carlo integration. 
Figure 1. Real exchange rate and stochastic macroeconomic trends.
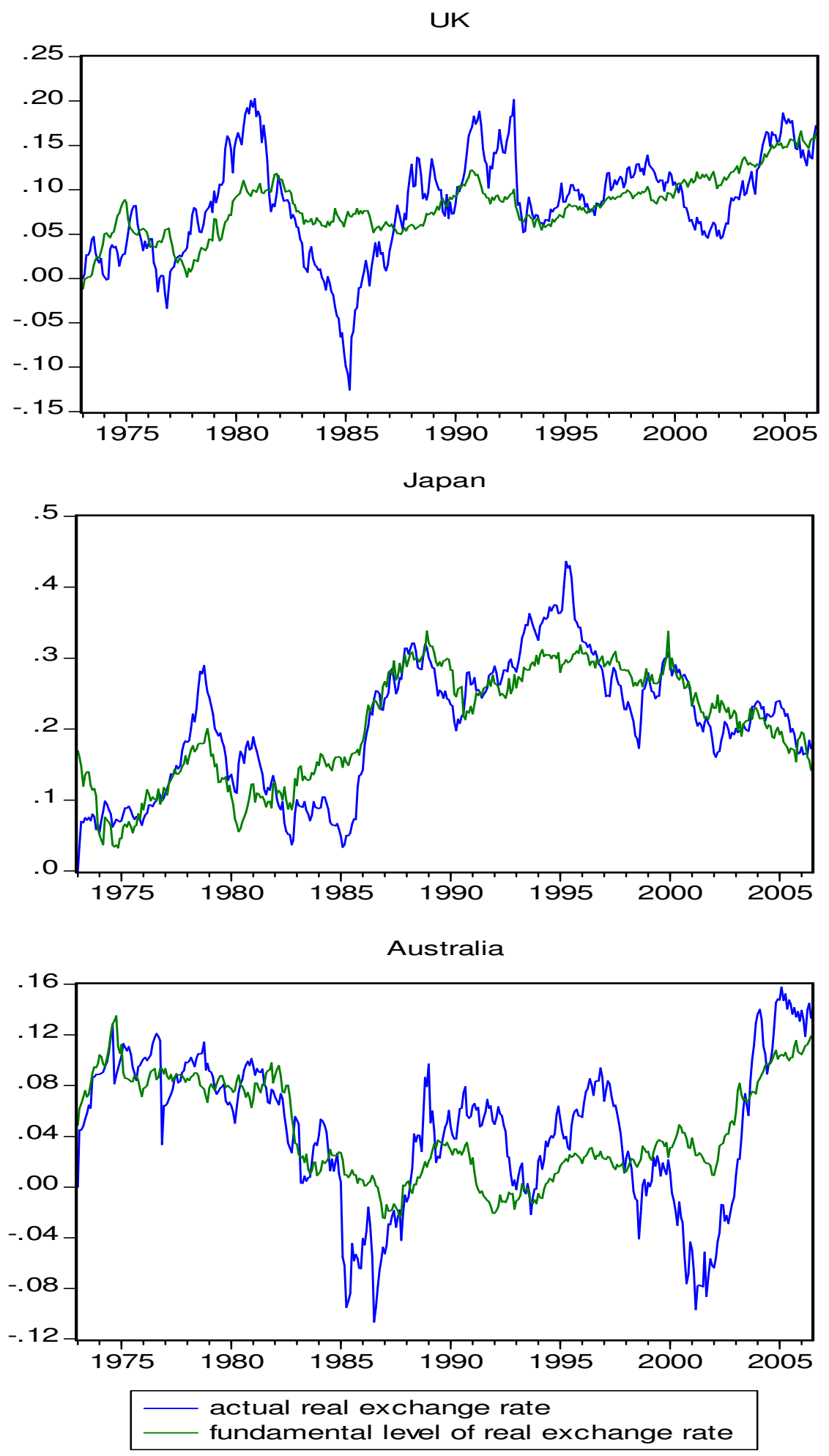
Figure 2. Impulse Response Functions
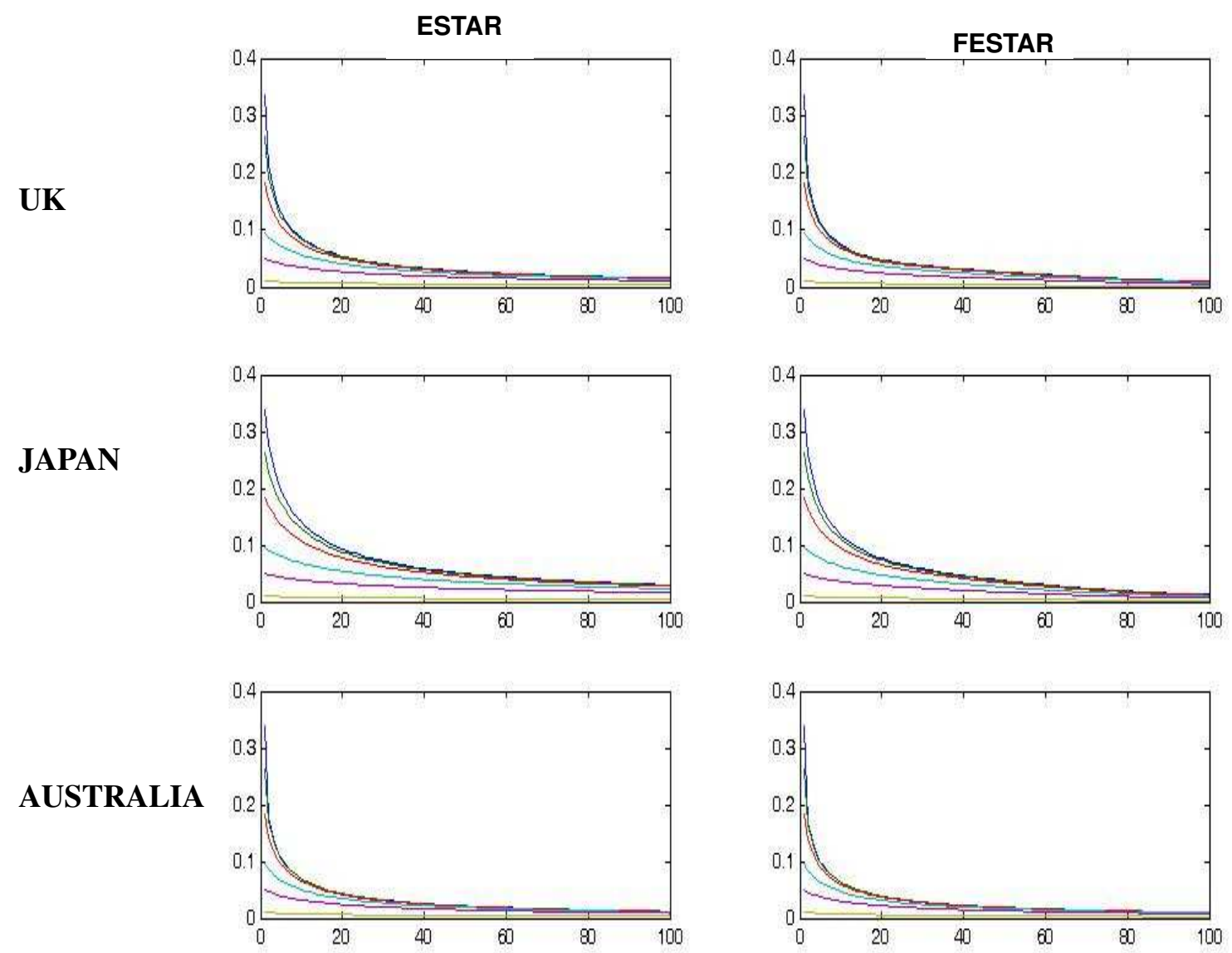

Note: Each line indicates the different sized shock. 